\title{
Laboratory Evaluation and Field Application of a Type of Surface-Active Polymer Oil Displacement Agent
}

\author{
Xiangbo Wei ${ }^{*}$, Xiaorui Li, Lei Wang, Guoyan Ma and Jinhao Gao
}

Key Laboratory of Auxiliary Chemistry \& Technology for Chemical Industry, Ministry of Education, Shaanxi University of Science \& Technology, Xi'an City, Shaanxi, 710021, PR. China

\begin{abstract}
Aiming to obtain a type of oil displacement with both surface activity and polymer performances, this paper, basing on mixing initiators at low temperatures, proposed a type of anion-nonionic surface-active polymer oil displacement agent (ANSP-1) by introducing polymerizable anion-nonionic surfmer (ANS-1), acrylamide (AM) and acrylic acid (AA). Structure of ANSP-1 was measured by FTIR. Laboratory studies show that: ANS-1 graft copolymerization occurs with AM, it avoids chromatographic separation, and it has better performances on molecular properties, such as tackifying performance, salt resistance, shear resistance and thermal stability. Oil-water interfacial tension can reach $1 \times 10^{-1} \mathrm{mN} / \mathrm{m}$. Field application shows that average recovery ratio of the test wells which used ANSP-1 is $11 \%$, which is $6.2 \%$ higher than the whole area.
\end{abstract}

Keywords: Low interfacial tension, Oil displacement agent, Polymer flooding, Recovery ratio.

\section{INTRODUCTION}

Polymer flooding technology is mainly based on increasing displacing fluid viscosity and reducing displacingdisplaced phase mobility ratio to improve reservoir coverage, thereby oil recovery ratio can be enhanced [1-3]. At present, oil displacement used polyacrylamides and their modified products appear with disadvantages on poor stability, temperature resistance and salt tolerance. Their viscosity will be greatly reduced in situations of high heat and high salinity [4]. Surfactant flooding technology mainly depends on reducing oil-water interfacial tension, improving surface charge density and changing wettability of the rocks, to reduce residual oil saturation of the reservoir. Thus, oil displacement efficiency and recovery ratio can be enhanced [5]. Enhanced oil recoveries (EOR) used surfactants that are mainly anionic and nonionic surfactants; most of them have disadvantages of poor adsorptive property, temperature resistance and salt tolerance [6].

It shows that there exists migration speed difference among the components of polymer/surfactant (PS), alkali/ polymer/ surfactant (APS) flooding technology, which can lead to chromatographic separation, leading to weakening of synergies between different oil displacement agents. Therefore, oil displacement efficiency of the system will be abated [7].

For the above reasons, in this paper based on mixing initiators at low temperatures, a type of anion-nonionic surfaceactive polymer oil displacement agent (ANSP-1) has been prepared with both surface activity and polymer performances

\footnotetext{
*Address correspondence to this author at the Key laboratory of Auxiliary Chemistry \& Technology for Chemical Industry, Ministry of Education, Shaanxi University of Science \& Technology, Xi'an City, Shaanxi, 710021, PR. China; Tel: 18729518299; Fax: 029-83113168;

E-mail:87052007@163.com
}

by introducing polymerizable anion-nonionic surfmer (ANS1), acrylamide (AM) and acrylic acid (AA). Structure of ANSP-1 was measured by FTIR, and its laboratory evaluation and field application were also researched.

\section{EXPERIMENTAL}

\subsection{Materials}

Polymerizable anion-nonionic surfmer (ANS-1) was prepared by Key Laboratory of Auxiliary Chemistry \& Technology for Chemical Industry (China). Acrylamide (AM), hydrolyzed polyacrylamide $\left(\mathrm{HPAM}, \mathrm{M}_{W}=200 \times 10^{4}\right)$ and salt-tolerant polymer (STP, $\mathrm{M}_{W}=180 \times 10^{4}$ ) were provided by Mitsui Chemicals (Japan). Low temperature composite initiator (LTC-1) and acrylic acid (AA) were supplied by Tianjin Hongyan Chemical Reagent Factory (China). Laboratorial cores $\left(\Phi=25 \mathrm{~mm} \times 70 \mathrm{~mm}\right.$, permeability $\left.44 \times 10^{-3} \sim 1050 \times 10^{-3}{\mu \mathrm{m}^{2}}^{2}\right)$ were offered by Changqing Oilfield (China). The crude oil used in this study was also obtained from Changqing oilfield, with a water content of less than $0.5 \%$, a density of 816.5 $\mathrm{kg} / \mathrm{m}^{3}$ and viscosity $32.5 \mathrm{mPa} \cdot \mathrm{s}$ at $45^{\circ} \mathrm{C}$.

According to SY/T 5862-2008 (technical criterions of polymer for oil displacement), standard brine was prepared with salinity as follows: $(\mathrm{mg} / \mathrm{L}), \mathrm{CaCl}_{2} 1143, \mathrm{MgCl}_{2} 863$, $\mathrm{NaCl} 17458$, total salinity of the standard brine for all the tests was $19334 \mathrm{mg} / \mathrm{L}$.

\subsection{Preparation of ANSP-1}

A certain mass ratio of AM, AA, ANS- 1 and deionized water were put into the four-necked flask with an electric mixer, and $\mathrm{N}_{2}$ continuously filled the reactor for $30 \mathrm{~min}$ until the water bath heated up to $30{ }^{\circ} \mathrm{C}$, then LTC-1 was added. The reaction was remained at $30^{\circ} \mathrm{C}$ for $6 \mathrm{~h}$ in the condition of filling $\mathrm{N}_{2}$, and the final product was washed by ethyl al- 
cohol for several times. Then vacuum drying was done up to constant weight at $60{ }^{\circ} \mathrm{C}$. Finally, ANSP-1(white powder, 90\% solid content) was obtained, as shown in Fig. (1).

\subsection{FTIR Characterization}

By uniformly dispersing the solid samples into potassium bromide, IR absorption spectra were obtained from 500 4000 wavenumbers $\left(\mathrm{cm}^{-1}\right)$ through a Vertex 80 FTIR spectrometer (Bruker Corporation, Germany) in a dry atmosphere.

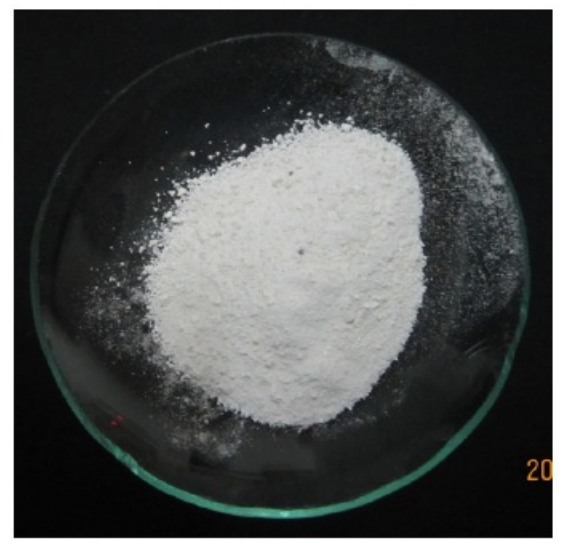

Fig. (1). Product Appearance of ANSP-1.

\subsection{Molecular Properties Measurements}

According to SY/T 5862-2008 (technical criterions of polymer for oil displacement), basic physical and chemical qualities of ANSP-1 were measured in standard brine.

An NDJ28S rotary viscometer (Shanghai Analytical Instrument Factory, China) was used to measure apparent viscosity of the samples.

\subsection{Salt Resistance Measurements}

Changes of polymer molecules line group size is mainly caused by electric forces between the ions, thereby concept of equivalent hydrodynamic volume of sphere was introduced by Fox Flory. Polymer molecules line group that continued doing thermal motion was considered as an equivalent ball with a diameter of $D_{\mathrm{h}}[8]$.

According to SY/T 5862-2008 (technical criterions of polymer for oil displacement), a BI-200SM wide dynamic/ static laser light scattering instrument (Brookhaven Instruments Company, U.S.) was used to describe $D_{\mathrm{h}}$. Expansion ratio of molecules line group $(E)$ that used to measure salt resistance of the polymers was defined as follows:

$E=\frac{D_{h 2}-D_{h 1}}{D_{h 1}} \times 100 \%$

where $D_{\mathrm{h} 1}$ was original molecules line group size of the polymer solution, and $D_{\mathrm{h} 2}$ was final molecules line group size of the polymer solution.

\subsection{Rheological Behavior Analysis}

According to SY/T 5862-2008 (technical criterions of polymer for oil displacement), an AR2000ex coaxial cylin- der rotary rheometer (TA Instruments Company, U.S.) was used for rheological behavior measurement, the measuring conditions were as follows: polymer solution was prepared with standard brine at concentration of $1500 \mathrm{mg} / \mathrm{L}$, the samples were stirred for 10 minutes at $75{ }^{\circ} \mathrm{C}$ and shearing rate of $7.34 \mathrm{~s}^{-1}$, then shear viscosity of the samples were measured, shear viscosity retention rate $(\Psi)$ that used to measure salt resistance of the polymer was defined as follows:

$\Psi=\frac{\eta_{2}}{\eta_{1}} \times 100 \%$

where $\eta_{1}$ was original shear viscosity of the polymer solution, and $\eta_{2}$ was shear viscosity of the polymer solution after shearing action.

\subsection{Oil-Water Interfacial Tension Measurements}

According to SY/T 6424-2000 (analytical method of alkaline/surfactant/polymer flooding system), a TX 500C spinning drop interface tensiometer (Kono Industrial Company, U.S.) was applied to interfacial tension tests at $45^{\circ} \mathrm{C}$, with revolving speed of $5000 \mathrm{r} / \mathrm{min}$.

The crude oil was loaded into a syringe and then injected through a syringe into an optical glass cuvette containing standard brine with different concentrations of oil displacement agents. The profile of the droplet was captured using a CCD camera and analyzed using a video image profile digitizer board connected to a computer. When the experiments were carried out, the volume of the drop was manipulated by software so that the area of the droplet oscillated sinusoidally [9].

\subsection{Thermal Stability Studies}

According to SY/T 5862-2008 (technical criterions of polymer for oil displacement), polymer solution samples were formulated using standard brine at a concentration of $0.15 \%$. Then the samples were loaded into $50 \mathrm{~mL}$ sealed tubes, after $\mathrm{O}_{2}$ was emptied by $\mathrm{N}_{2}$. The samples were placed into a drying oven for 30,60 and 90 days at $75{ }^{\circ} \mathrm{C}$. Finally viscosity and viscosity retention rate of the samples were tested.

Viscosity retention rate $(N)$ that used to measure thermal stability of the polymers was defined as follows:

$N=\frac{\eta_{4}}{\eta_{3}} \times 100 \%$

where $\eta_{3}$ was original viscosity of the sample, and $\eta_{4}$ was viscosity of the sample after aging test.

\subsection{Simulated Oil Displacement Experiments}

According to SY/T 6424-2000 (analytical method of alkaline/surfactant/polymer flooding system), a parallel-sand pack flow test installation was used for simulated oil displacement experiment in the laboratory. The experimental installation consisted of a syringe pump, two cylinders, two sand packs and a pressure transducer connected to a computer for recording the inlet pressure. Flooding cores which was used for the experiments were Changqing Cheng 95 natural cores. All tests were conducted at $45^{\circ} \mathrm{C}[10]$. 
Firstly, flooding out the oil until the water content exceeded $98 \%$, then $1 / 2 \mathrm{PV}$ (injected pore volume ratio) ANSP-1 solution was injected, flooding to stop at $98 \%$ water content [11].

Finally, recovered oil was collected, and recovery ratio of the sample $(E r)$ was calculated as follows:

$$
E r=\frac{V_{2}}{V_{1}} \times 100 \%
$$

where $V_{1}$ was original oil volume, and $V_{2}$ was displacement oil volume.

\section{RESULTS AND DISCUSSION}

\subsection{Effects of ANS-1 Concentration on ANSP-1}

Under the condition that reaction temperature was $30^{\circ} \mathrm{C}$, LTC-1 mass fraction was $0.003 \% \sim 0.005 \%$. By varying ANS1 concentration, this paper prepared a series of ANSP-1. Then effects of ANS-1 concentration on ANSP-1 performances were investigated, the results were shown in Table $\mathbf{1 .}$

As shown in Table 1, interfacial tension of polymer solution (ANSP-1), which was graft-copolymerized by AM and ANS- 1 can be reduced to $1 \times 10-1 \mathrm{mN} / \mathrm{m}$. As ANS- 1 concentration is increased, the ability to reduce the interfacial tension of ANSP-1 increased, but its molecular weight decreased. Taking into account tackifying performance and oil-water interfacial tension, ANS-1 concentration is controlled at $2 \sim 3 \%$.

Table 1. Relationship between ANSP-1 properties \& ANS-1 concentration.

\begin{tabular}{|c|c|c|c|}
\hline Products & $\begin{array}{c}\text { ANS-1 } \\
\text { Concentration (\%) }\end{array}$ & $\begin{array}{c}\text { Interfacial Tension } \\
(\mathbf{m N} / \mathbf{m})\end{array}$ & $\begin{array}{c}\mathbf{M w} \\
\left(\times \mathbf{1 0}^{\mathbf{4}}\right)\end{array}$ \\
\hline \hline 1 & 1.0 & 0.810 & 198 \\
\hline 2 & 1.5 & 0.654 & 185 \\
\hline 3 & 2.0 & 0.538 & 173 \\
\hline 4 & 2.5 & 0.452 & 160 \\
\hline 5 & 3.0 & 0.240 & 145 \\
\hline
\end{tabular}

\subsection{FTIR Analysis of ANSP-1}

Most performances of the polymer are strongly affected by the degree of bands, so any factor which can increase bands is very important to study in this case [12]. FTIR spectra of ANSP-1 are shown in Fig. (2), the main bands of ANSP-1 with corresponding functional groups are given in Table 2.

Seen from Fig. (2), the -C-O characteristic absorption peak in the spectra of ANSP-1 appears at wave number 1110 $\mathrm{cm}^{-1}$. The $-\mathrm{SO}_{3} \mathrm{H}$ characteristic absorption peak in the spectra of ANSP-1 appears at wave number $1250 \mathrm{~cm}^{-1}$ and $1040 \mathrm{~cm}^{-}$ ${ }^{1}$, which proves that ANS-1 took part in the polymerization.

\subsection{Laboratory Evaluation of ANSP-1}

\subsubsection{Molecular Properties}

Basic physical and chemical qualities of ANSP-1, hydrolyzed polyacrylamide (HPAM) and salt-tolerant polymer (STP) were researched in standard brine, as shown in Table 3.

Seen from Table 3, basic physical and chemical qualities of ANSP-1 are between HPAM and STP, which proves that ANSP-1 is suitable for polymer flooding [13].

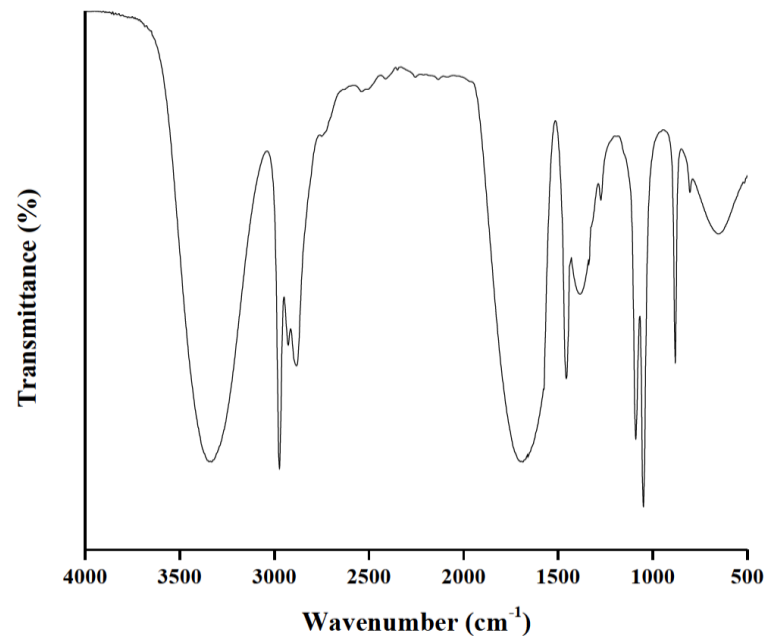

Fig. (2). FTIR Spectra of ANSP-1.

Table 2. FTIR spectral data of ANSP-1.

\begin{tabular}{|c|c|}
\hline Band Position $\left(\mathrm{cm}^{-1}\right)$ & Functional Groups \\
\hline $3250-3450$ & -NH stretching vibrations \\
\hline $2860-2950$ & $\begin{array}{c}-\mathrm{CH}_{2} \text { symmetric and anti-symmetric } \\
\text { stretching vibrations }\end{array}$ \\
\hline $1670-1750$ & $>\mathrm{C}=\mathrm{O}$ stretching vibrations \\
\hline $1420-1480$ & $>\mathrm{C}-\mathrm{N}$ and in plane $-\mathrm{N}-\mathrm{H}$ deformation \\
\hline $1050-1150$ & -O-C stretching of urethane/ester group \\
\hline
\end{tabular}

\subsubsection{Molecular Properties}

By increasing oil-water mobility ratio and apparent viscosity of the displacing fluid, liquid polymer can increase swept volume of the displacing fluid, thereby enhancing oil recovery. Generally speaking, in the same structure of the polymer, greater relative molecular mass bring stronger thickening capacity [14]. Fig. (3) described apparent viscosity of different polymers prepared in standard brine.

As shown in Fig. (3), in the condition of same polymer mass fraction, tackifying performance of ANSP-1 is better than ordinary HPAM, and close to STP. This is mainly due to intermolecular forces among the hydrophobic groups of ANSP-1, these hydrophobic groups form supramolecular structure-dynamic physical crosslinking network, causing hydrodynamic volume increase, which results in a substantial rise in the solution viscosity. 
Table 3. Molecular properties of different polymers.

\begin{tabular}{|c|c|c|c|c|c|c|}
\hline Polymers & $\begin{array}{c}\text { Dissolution Time } \\
(\mathbf{m i n})\end{array}$ & Solid Content (\%) & $\begin{array}{c}\text { Hydrolysis } \\
\text { Degree (mol\%) }\end{array}$ & Mw $\left(\times \mathbf{1 0}^{\mathbf{4}}\right)$ & $\begin{array}{c}\text { Apparent } \\
\text { Viscosity (mPa·s) }\end{array}$ & $\begin{array}{c}\text { Water Insoluble } \\
\mathbf{( \% )}\end{array}$ \\
\hline \hline ANSP-1 & 90 & 90.4 & 22.5 & 170 & 19.2 & 0.420 \\
\hline HPAM & 90 & 92.5 & 26.4 & 200 & 16.8 & 0.286 \\
\hline STP & 90 & 87.5 & 28.2 & 180 & 22.4 & 0.254 \\
\hline
\end{tabular}

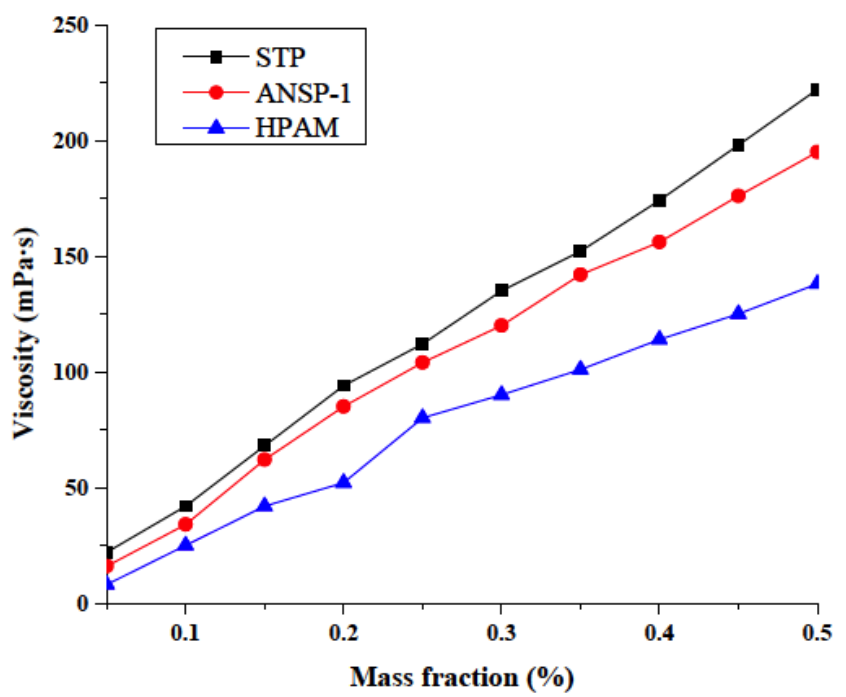

Fig. (3). Tackifying Performance of Polymers.

Table 4. Coil shape size of molecular chain of different polymers.

\begin{tabular}{|c|c|c|c|c|}
\hline \multirow{2}{*}{ Polymers } & \multicolumn{4}{|c|}{$D_{\text {h Values for Different Polymer Concentrations (nm) }}$} \\
\cline { 2 - 5 } & $\mathbf{0 . 1 \%}$ & $\mathbf{0 . 3 \%}$ & $\mathbf{0 . 5 \%}$ & Expansion Ratio (E) (\%) \\
\hline \hline ANSP-1 & 122.5 & 492.3 & 484.2 & $\mathbf{5 4 0 . 2 \%}$ \\
\hline HPAM & 102.3 & 208.2 & 410.6 & $\mathbf{3 0 1 . 4 \%}$ \\
\hline
\end{tabular}

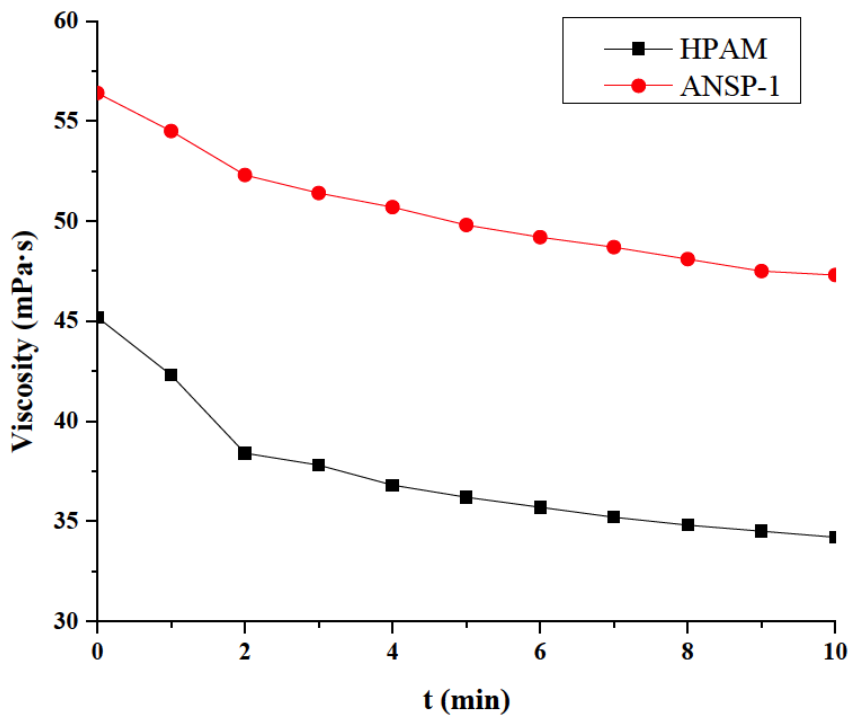

Fig. (4). Relationship between viscosity \& time. 
Table 5. Interfacial tension among polymer solution and Changqing oil of different concentrations.

\begin{tabular}{|c|c|c|c|c|c|}
\hline \multirow{2}{*}{ Polymers } & \multicolumn{5}{|c|}{ Interfacial Tension (mN/m) } \\
\cline { 2 - 6 } & $\mathbf{0 . 0 5 \%}$ & $\mathbf{0 . 1 0} \%$ & $\mathbf{0 . 1 5 \%}$ & $\mathbf{0 . 2 0} \%$ & 0.381 \\
\hline \hline ANSP-1 & 0.952 & 0.763 & 0.541 & 11.260 & 0.260 \\
\hline HPAM & 10.012 & 10.482 & 10.958 & 11.012 & 11.975 \\
\hline STP & 9.830 & 10.223 & 10.780 & 11.608 \\
\hline
\end{tabular}

Table 6. Interfacial tension of ANSP-1 and Changqing oil before and after purification.

\begin{tabular}{|c|c|c|c|c|}
\hline \multirow{2}{*}{ Polymers } & \multicolumn{3}{|c|}{ Interfacial Tension of ANSP-1 Solution on Different Time (mN/m) } \\
\cline { 2 - 5 } & $\mathbf{1 0 ~} \mathbf{m i n}$ & $\mathbf{3 0 ~} \mathbf{m i n}$ & $\mathbf{6 0} \mathbf{~ m i n}$ & $\mathbf{9 0} \mathbf{~ m i n}$ \\
\hline \hline Unpurified ANSP-1 & 1.043 & 0.846 & 0.720 & 0.732 \\
\hline Purified ANSP-1 & 1.062 & 0.883 & 0.552 \\
\hline
\end{tabular}

Table 7. Thermal stability between ANSP-1 and HPAM.

\begin{tabular}{|c|c|c|c|c|}
\hline \multirow{2}{*}{ Aging Time (d) } & \multicolumn{2}{|c|}{ ANSP-1 } & \multicolumn{2}{|c}{ HPAM } \\
\cline { 2 - 5 } & Viscosity (mPa·s) & Viscosity Retention (\%) & Viscosity (mPa·s) & Viscosity Retention (\%) \\
\hline \hline 0 & 56.4 & 100.0 & 45.2 & 36.8 \\
\hline 30 & 51.0 & 90.5 & 32.6 & 81.5 \\
\hline 60 & 47.8 & 85.4 & 28.7 & 72.2 \\
\hline 90 & 45.8 & 81.2 & 63.5 \\
\hline
\end{tabular}

\subsubsection{Salt Resistance}

On a micro level, salt resistance of polymer solution is manifested as changes in coil shape size of its molecular chain [15]. Table 4 shows coil shape size of molecular chain of different polymers.

Seen from Table 4, at the same concentration, ANSP-1 has a larger coil shape size of molecule chain than HPAM, indicating that salt resistance of ANSP-1 is better than HPAM. The reason for this phenomenon is: ANSP-1 introduced some hydrophilic groups with strong salt resistance, such as acylamino, sulfonic acid group and polyether, etc. Electrostatic repulsion among these groups makes their distances farther away, thus forming a large hydrodynamic volume, so that polymer solution gets a high viscosity on a macro-scale [16]. Even due to hydrophobic association, viscosity of the polymer in saline may be higher than in fresh water.

\subsubsection{Shear Resistance}

When polymer solution is injected into the stratum, its long-chain flexibility molecular bonds may be broken due to the shear action, resulting in the degradation of molecular weight and viscosity of the polymer. These phenomena will weaken the oil displacement efficiency.
After stirred in a high speed stirrer for 10 minutes, shear viscosity and shear viscosity retention rate of the polymers were measured, as shown in Fig. (4).

Seen from Fig. (4), at the same shear time, shear viscosity and shear viscosity retention rate of ANSP-1 are significantly superior to HPAM. This is mainly because ANSP-1 molecular chain introduces rigid surface active monomer. Due to steric hindrance of these rigid side groups, molecular motion resistance becomes large, and shear viscosity of the polymer solution is reduced to a lesser extent [17].

Shear viscosity retention rate of HPAM is $75 \%$, while shear viscosity retention rate of ANSP-1 is $85 \%$, which is significantly better than HPAM.

\subsubsection{Oil-Water Interfacial Tension}

Formation of low interfacial tension is a key factor of chemical flooding to enhance oil recovery. Ultra-low interfacial tension makes oil droplets that are attached to the cores and moved easily, so that resistance to flow through the pores throat is reduced [18]. These are all in favor of enhanced oil recovery.

(1) Interfacial tension between different concentrations of ANSP-1 solution and Changqing oil were measured in standard brine, as shown in Table 5. Seen from Table 5, 
Table 8. Simulated oil displacement experiments of different polymers.

\begin{tabular}{|c|c|c|c|c|}
\hline \multirow{2}{*}{ Polymers } & \multirow{2}{*}{ Oil Saturation (\%) } & \multicolumn{4}{|c|}{ Recovery Ratio (\%) } \\
\cline { 3 - 5 } & & Water Drive & Polymer Flooding & Amplification (\%) \\
\hline \hline ANSP-1 & 73.5 & 42.1 & 55.3 & $\mathbf{1 3 . 2}$ \\
\hline HPAM & 72.6 & 38.7 & 47.2 & $\mathbf{8 . 5}$ \\
\hline STP & 70.4 & 39.2 & 49.4 & $\mathbf{1 0 . 2}$ \\
\hline
\end{tabular}

Table 9. Recovery ratio of ANSP-1.

\begin{tabular}{|c|c|c|c|c|c|}
\hline Wells & Reservoirs & Oil Saturation (\%) & \multicolumn{3}{|c|}{ Recovery Ratio (\%) } \\
\hline 2 & Chang $7_{2}$ & 53.8 & 31.2 & 12.6 & 43.8 \\
\hline 3 & Chang $7_{2}$ & 59.8 & 32.5 & 11.8 & 44.3 \\
\hline 5 & Chang $7_{2}$ & 61.7 & 41.2 & 13.8 & 55.0 \\
\hline \multicolumn{2}{|c|}{ Average of test wells (5) } & 55.3 & 35.2 & 11.0 & 46.3 \\
\hline \multicolumn{2}{|c|}{ Average of the area (120) } & 53.2 & 30.5 & 4.8 & 35.3 \\
\hline
\end{tabular}

ANSP-1 is much better than HPAM on reducing interfacial tension at the same concentration.

(2) In the condition of $0.15 \%$ concentrations, interfacial tension between ANSP-1 and Changqing oil was measured before and after purification in standard brine, as shown in Table 6. Seen from Table 6, before and after purification, dynamic interfacial tensions of ANSP-1 are close, which indirectly proves that major ANS-1 is grafted onto the polymer main chain, instead of blending of surfactant monomer and polymer, so that it fundamentally avoids chromatographic separation.

\subsubsection{Thermal Stability}

EOR used polymer must have good thermal stability, in order to maintain long-term thickening ability underground. Viscosity and viscosity retention of different polymers which placed in the oven for some time at $75{ }^{\circ} \mathrm{C}$ were tested, as shown in Table 7.

Seen from Table 7, ANSP-1 has better viscosity and viscosity retention than HPAM under the same conditions. The reason is that introduction of long carbon chain and rigid groups increase thermal motion resistance of the polymer solution, thus thermal stability of the system is improved [19].

\subsubsection{Simulated Oil Displacement Experiments}

A displacement installation was used for simulated oil displacement experiments in laboratory, the experimental results are shown in Table $\mathbf{8}$.

Seen from Table 8, on the same amount of polymer conditions, recovery ratio of ANSP-1 is $13.2 \%$, which is $4.7 \%$ higher than HPAM. Analysis shows that viscosity of ANSP-
1 solution is larger, it has a strong flow control capability, can effectively expand the swept volume, and has certain ability for washing oil, so oil recovery increase is larger [20].

\subsection{Field Application}

So far, ANSP-1 has been used in 5 test wells of Changqing Oilfield. Application results are shown in Table 9. As shown in Table 9, average recovery ratio of the test wells is $11 \%$, which is $6.2 \%$ greater than the whole area, means ANSP-1 is worth promoting.

\section{CONCLUSION}

In this study, laboratory evaluation and field application were conducted to research the performances of anionnonionic surface-active polymer oil displacement agent (ANSP-1) for EOR; major conclusions drawn from this study are as follows:

1. ANSP-1 introduces polymerizable anion- nonionic surfmer (ANS-1), has both surfactant and polymeric properties, and avoids chromatographic separation.

2. Laboratory evaluation shows that ANSP-1 has better performances on molecular properties, such as tackifying performance, salt resistance, shear resistance and thermal stability. Oil-water interfacial tension can reach $1 \times 10^{-1}$ $\mathrm{mN} / \mathrm{m}$. Simulated oil displacement experiments show that recovery ratio of ANSP-1 is $4.7 \%$ higher than HPAM.

3. Field application shows that average recovery ratio of the test wells which used $11 \%$ ANSP-1, is $6.2 \%$ higher than the whole area, means ANSP-1 is worth promoting. 


\section{CONFLICT OF INTEREST}

The authors confirm that this article content has no conflict of interest.

\section{ACKNOWLEDGEMENTS}

This work is financially supported by Oil \& Gas Technology Research Institute of Petro China Changqing Oilfield and Key laboratory of Auxiliary Chemistry \& Technology for Chemical Industry of Shaanxi University of Science \& Technology.

The authors acknowledge with thanks the financial support from The Major Scientific and Technological Innovation Foundation of Shaanxi Province, China (Project No.: 2011zkc04-3) and Research On ASP Flooding in Low Permeability Reservoir Project of Changqing Oilfield Company, China.

\section{REFERENCES}

[1] J. Wang, H.Q. Liu, Z.F. Ning, H.L. Zhang, and C. Hong, "Experiments on water flooding in fractured-vuggy cells in fracturedvuggy reservoirs", Pet. Explor. Dev. China, vol. 41, no. 1, pp. 7481, February 2014.

[2] Y.Y. Zhu, Q.F. Hou, G.Q. Jian, D.S. Ma, and Z. Wang, "Current development and application of chemical combination flooding technique", Pet. Explor. Dev. China, vol. 40, no. 1, pp. 96-103, February 2013.

[3] Z.J. Song, L.B. Liu, M.Z. Wei, B.J. Bai, J.R. Hou, Z.P. Li, and Y.P. $\mathrm{Hu}$, "Effect of polymer on disproportionate permeability reduction to gas and water for fractured shales", Fuel. England, vol. 143, pp. 28-37, March 2015.

[4] B.Y. Jamaloei, R. Kharrat, and K. Asghari, "The influence of salinity on the viscous instability in viscous-modified low-interfacial tension flow during surfactant-polymer flooding in heavy oil reservoirs", Fuel. England, vol. 97, pp. 174-185, July 2012.

[5] B.Y. Jamaloei, R. Kharrat, K. Asghari, and F. Torabi, "The influence of pore wettability on the microstructure of residual oil in surfactant-enhanced water flooding in heavy oil reservoirs: Implications for pore-scale flow characterization”, J. Pet. Sci. Eng. Netherlands, vol. 77, no. 1, pp. 121-134, April 2011.

[6] K. Rai, R.T. Johns, M. Delshad, L.W. Lake, and A. Goudarzi, "Oilrecovery predictions for surfactant polymer flooding", J. Pet. Sci. Eng. Netherlands, vol. 112, pp. 341-350, December 2013.

[7] K.M. Ko, B.H. Chon, S.B. Jang, and H.Y. Jang, "Surfactant flooding characteristics of dodecyl alkyl sulfate for enhanced oil recovery", J. Ind. Eng. Chem. South Korea, vol. 20, no. 1, pp. 228-233, 25 January 2014.
[8] G.W. Fu, G. Li, and K.C. Feng. Macromolecular Physics. Beijing, CA: Chemical Industry Press: 2004.

[9] B. Wang, T. Wu, Y.J. Li, D.J. Sun, M. Yang, Y.X. Gao, F.J. Lu, and $\mathrm{X}$. Li, "The effects of oil displacement agents on the stability of water produced from ASP (alkaline/surfactant/polymer) flooding", Colloids Surf., A: Phys. Eng. Asp. Netherlands, vol. 379, no. 1-3, pp. 121-126, 20 April 2011.

[10] R.Y. Cao, H.J. Yang, W. Sun, and Y.Z. Ma, "A new laboratory study on alternate injection of high strength foam and ultra-low interfacial tension foam to enhance oil recovery", J. Pet. Sci. Eng. Netherlands, vol. 125, pp. 75-89, January 2015.

[11] Z. Hua, M.Q. Lin, Z.X. Dong, M.Y. Li, G.Q. Zhang, and J. Yang, "Study of deep profile control and oil displacement technologies with nanoscale polymer microspheres", J. Colloid Interface Sci., vol. 424, pp. 67-74, 15 June 2014.

[12] L.F. Chen, G.C. Zhang, J.J. Ge, P. Jiang, J.Y. Tang, and Y.L. Liu, "Research of the heavy oil displacement mechanism by using alkaline/surfactant flooding system", Colloids Surf. A: Phys. Eng. Asp. Netherlands, vol. 434, pp. 63-71, 5 October 2013.

[13] C.Y. Hung, S.J. Hsieh, C.C. Wang, and C.Y. Chen, "Structural characterization and thermal behavior of dendritic-linear PGMAHPAM-r-PS copolymers in a self-assembled microporous matrix", Polym. Degrad. Stab. United Kingdom, vol. 98, no. 6, pp. 11961204, June 2013.

[14] A.R. Al Hashmi, R.S. Al Maamari, I.S. Al Shabibi, A.M. Mansoor, A. Zaitoun, and H.H. Al Sharji, "Rheology and mechanical degradation of high-molecular-weight partially hydrolyzed polyacrylamide during flow through capillaries", J. Pet. Sci. Eng. Netherlands, vol. 105, pp. 100-106, May 2013.

[15] L. Zhao, A.F. Li, K. Chen, J.J. Tang, and S.S. Fu, "Development and evaluation of foaming agents for high salinity tolerance", $J$. Pet. Sci. Eng. Netherlands, vol. 81, pp. 18-23, January 2012.

[16] A.M. Mansour, R.S. Al-Maamari, A.S. Al-Hashmi, A. Zaitoun, and H. Al-Sharji, "In situ rheology and mechanical degradation of EOR polyacrylamide solutions under moderate shear rates", J. Pet. Sci. Eng. Netherlands, vol. 115, pp. 57-65, March 2014.

[17] M.A. Ahmadi, and S.R. Shadizadeh, "Implementation of a highperformance surfactant for enhanced oil recovery from carbonate reservoirs", J. Pet. Sci. Eng. Netherlands, vol. 110, pp. 66-73, October 2013.

[18] B.I. Choi, M.S. Jeong, and K.S. Lee, "Temperature-dependent viscosity model of HPAM polymer through high-temperature reservoirs", Polym. Degrad. Stab. United Kingdom, vol. 110, pp. 225 231, December 2014.

[19] R.G. dos Santos, A.C. Bannwart, and W. Loh, "Phase segregation, shear thinning and rheological behavior of crude oil-in-water emulsions", Chem. Eng. Res. Des., vol. 92, no. 9, pp. 1629-1636, September 2014

[20] H.H. Al-Attar, "Evaluation of oil foam as a displacing phase to improve oil recovery", J. Pet. Sci. Eng. Netherlands, vol. 79, no. 34, pp. 101-112, November 2011.

(C) Wei et al.; Licensee Bentham Open.

This is an open access article licensed under the terms of the Creative Commons Attribution Non-Commercial License (http://creativecommons.org/licenses/by-nc/4.0/) which permits unrestricted, non-commercial use, distribution and reproduction in any medium, provided the work is properly cited. 